\title{
DISEÑA 18:
}

History of Desigh,Techniques, and Technology

1 We are using the category of technology to refer to a specific field of study defined as History of Technology. Its broader, universal, and general use has been avoided, referring in each case to objects, machines, or infrastructures that are frequently gathered under its use.
This edition focuses on the histories of design, techniques, and technology. ${ }^{1}$ The scholarly work that links them has generated a growing number of research and publications, revealing the diversity and richness offered by this interdisciplinary intersection.

This issue gathers an entanglement of the historical, cultural, and technical conditions of objects, images, and infrastructures, integrating diverse perspectives from design, as well as from the history of technology, engineering, sts (science and technology studies), material culture studies, and gender studies. In many cases, these perspectives are overlapped and combined loosely and unorthodoxly by analyses of and through design.

The relationship between the history of design, techniques, and technology can contribute to the promotion of new perspectives on technical objects and infrastructures that consider, for example, the dimension of use, experience, and meaning involved in the various phases of the life cycle of the product. In turn, focus on the notions of use entails a situated view for the articulation of the analysis of local strategies and intentions that allow us to overcome the creation of narratives that are distant from the socio-technical and territorial linkages that contextualize and define their action. As David Edgerton (Edgerton, 2007) points out, this option enables an interesting historiographic perspective based on the use of technical objects and products, which leads to rethinking the conception of which have been the most transcendent technical solutions concerning the experiences and meanings for the people and populations who use them. Consequently, with this new approach, "we shift attention from the new to the old, the big to the small, the spectacular to the mundane, the masculine to the feminine, the rich to the poor" (Edgerton, 2007, p. 15). Thus, it is important to broaden the views regarding technical activity and production, dismantle some myths about the utopia of its unlimited benefits, its neutrality, its universality, and the transfer of hegemonic and foreign models without dimensioning social, economic, and cultural differences. 
The dialogue between points of view, characteristic of design as a discipline (such as the use and user category), and perspectives from other disciplinary fields such as anthropology and intersectionality and gender studies, among others, allows us to approach non-binary conceptions of the technical phenomenon that, instead of being situated in cultural or technological determinism, explore the set of relationships between culture and technique, integrating decolonial, systemic, and ontological perspectives. This issue of Diseña proposes a historiographic approach that considers a broader and plural sociotechnical framework, made up of multiple nodes, which in turn includes the analysis of local strategies and intentions to rethink the history of design and its relationship with infrastructures and technical objects.

This issue invites us to think about the histories of design, techniques, and technology from deep ecology, beyond the connotations of progress and change defined by modernity. One that welcomes, among other things, the increasing technical changes in which the practice of designers is immersed, now converted into algorithmically assisted subjects and adjusted to an electronic administration of life (Sadin, 2017). In this sense, this issue presents contributions that account for the continuous technical development in which the practice of design is historically involved, promoting a critical reading of techniques and technical solutions, to examine their agencies and interrelations in a situated manner.

This issue was developed between 2019 and 2020 , years characterized by a radical social movement in Chile and the uncertainty of the pandemic generated by Covid-19 worldwide. Both events have been strongly marked by the use of digital infrastructures and technical objects, involving the organization of meetings, solidarity networks, and new forms of education, that have also been key in registering these same transformations. At the time of verifying its possibilities, we have witnessed its technical limitations, its manipulation, and its vulnerability, as it is marked by the agency of the platforms and algorithms that direct them (Dijck, 2013). In this context, while publishing this issue, the design and use of products, infrastructures, and technical activities have been rapidly modified, transforming the very dynamics of elaboration and organization of what today is materialized in this edition, as well as the place from which we understand, study, and value design, technique, and technical objects.

This issue includes contributions from various authors and case studies located in different territories, cultural contexts, and historical moments, that allow us to reflect upon the relationships between technique, technical objects, infrastructures, and design from different points of view and scales. Rodrigo Vera Manríquez and Bruno Perelli address the binomial 
art and technique in technical culture in Chile. Through the iconographic and semiotic analysis of images in artistic and industrial magazines published in Chile in the 1930s, the authors describe and analyze the relationship between machine and man as a fundamental axis to understand the technical phenomenon of the time, and also of the construction of the discipline of design in the country.

From another perspective, Yohad Zacarías addresses early electric lighting in Chile as a case study through the examination of advertisements (1900-1920) in times when automation processes were limited to defined and repetitive tasks, a phenomenon analyzed as technical controversy from an s Ts approach. Another view, located at the advent of the same infrastructure in Latin America and its course as one of the most powerful and disruptive forces in the region, focusing on the Peruvian case, is the object of José Ragas and Yenisa Guizado's analysis, who argue that electricity not only transformed urban life but also affected rural areas and their population with the same techno-utopian purpose.

Going back in time, Marina Garone Gravier and Daniel Silverman focus on material culture and graphic techniques in the Viceroyalty of Río de la Plata (Argentina), raising questions regarding the availability of printing tools and the paper supply in the $18^{\text {th }}$ century with minimal technologies. The article focuses on the analysis of Laudationes Quinque, the first book printed in the city of Córdoba in the colonial period, emphasizing the compositional aspects and elements of graphic communication that have been commonly relegated by historians and bibliographers.

On the other hand, Ellan Spero and Christine Ortiz propose to fix our gaze on the problem of scale, as a new lens for the history of technology, combined with perspectives from engineering and material sciences. The authors explore the different scales of a technical system, integrating the material scale as an active part of the technical landscape. Through the study of the materials that support the filtration of water in the $19^{\text {th }}$ century in the United States, Spero and Ortiz propose a study perspective that accounts for the social and material relationships transformed through scales, as a new focus for the study of a socio-technical system. From the interweaving between the history of technology, engineering, and the scientific research of materials, the authors present an original analytical perspective that is highly relevant for the history of design and its contemporary disciplinary practice.

On her part, Francesca Bray - interviewed by Nicole Cristi - explores the possibilities offered by a situated approach to the history of techniques and technology, combining perspectives from anthropology, feminism, and gender studies. In turn, David Edgerton - interviewed by Hugo 
Palmarola and Pedro Álvarez Caselli - addresses, from a critical perspective, the usefulness of the concept of 'technology' and sts (Science and Technology Studies) approaches within the practice and design studies. As a result, this edition contributes to the development of critical perspectives to reflect upon the relationship between the history of design, techniques, and technology, promoting pluralistic views based on situated realities and multiple study perspectives.

\section{REFERENCES}

DIJCK, J. VAN. (2013). The Culture of Connectivity: A Critical History of Social Media. Oxford University Press.

EDGERTON, D. (2007). Innovación y tradición. Historia de la tecnología moderna. Crítica. SADIN, É. (2017). La humanidad aumentada. La administración digital del mundo. Caja Negra. 